Journal of Animal and Veterinary Advances 10 (13): 1706-1710, 2011

ISSN: $1680-5593$

(C) Medwell Journals, 2011

\title{
Nephropathogenicity of H9N2 Avian Influenza Virus in Commercial Broiler Chickens Following Intratracheal Inoculation
}

\author{
M.M. Hadipour, S.H. Farjadian, F. Azad, M. Kamravan and A. Dehghan \\ Department of Veterinary Clinical Sciences, \\ Islamic Azad University, Kazerun Branch, Kazerun, Iran
}

\begin{abstract}
H9N2 avian influenza virus is responsible for the majority of death in Iranian poultry farms due to renal damage. For understanding the nephropathogenicity of H9N2 avian influenza virus in commercial broiler chickens, thirty 20 days old chickens were intratracheally inoculated with $10^{6} \mathrm{EID}_{50}$ per bird with $\mathrm{A} /$ Chicken/Iran/SH-110/99 (H9N2) avian influenza virus. Then on days 1, 2, 4, 6, 8 and 10 Post-Inoculation (PI) samples of the kidney were collected for histopathologic studies. In inoculated chickens tubulointerstitial nephritis in the kidney were observed on days 6,8 and $10 \mathrm{PI}$. The results indicated that the A/Chicken/Iran/SH110/99 (H9N2) avian influenza virus after IT inoculation has pathogenicity for kidney (nephrotropic).
\end{abstract}

Key words: H9N2, influenza, nephropathogenicity, commercial broiler chickens, avain, virus, Iran

\section{INTRODUCTION}

Avian influenza viruses are caused a viral, highly contagious disease of domestic and wild birds and can be classified into two different pathotypes (low and high pathogenicity), based on the ability to produce disease and death in the major domestic poultry species, the chicken (Gallus domesticus) (Alexander, 2000; Ron et al., 2005; Swayne, 2007).

Low Pathogenic Avian Influenza (LPAI) viruses are capable of replicating only in few organs, mainly the respiratory and GI tracts and do not invade the rest of the body. However, frequent incidences of high mortality have been reported in field situation in outbreaks of low pathogenic avian influenza viruses such as H9N2 subtypes (Bano et al., 2003; Naeem et al., 1999; Nili and Asasi, 2002, 2003).

Influenza A viruses of the H9N2 subtype have become highly prevalent in poultry in many countries and although, these viruses generally cause only mild to moderate disease, they have been associated with severe morbidity and mortality in poultry as a result of co-infection with other pathogens (Brown et al., 2006; Nili and Asasi, 2002, 2003).

Antigenic and genetic analyses of H9N2 viruses isolated during the last two decades indicate that these viruses are extensively evolving and have reassorted with other avian influenza viruses to generate multiple novel genotypes (Li et al., 2003, 2005; Xu et al., 2004, $2007 \mathrm{a}$, b). Prior to 1990 , H9N2 viruses were mainly detected in avian species in North America and healthy ducks during surveillance in Southeast China (Brown et al., 2006). In 1988, the isolation of an H9N2 virus from Japanese quail in Southern China was the 1st recorded land-based poultry case of H9N2 in Asia (Perez et al., 2003a, b; Fedorko and Nelson, 2006; Liu et al., 2003). Since, 1998, an outbreak of low pathogenic avian influenza virus (H9N2 subtype) has occurred in Iranian poultry industry (Nili and Asasi, 2002, 2003). The H9N2 subtype outbreaks have occurred in domestic ducks, chickens and turkeys in different parts of the world (Capua et al., 2000; Bano et al., 2003; Capua and Alexander, 2004; Naeem et al., 1999; Alexander, 2000; Nili and Asasi, 2002, 2003). More recently, H9N2 viruses have been reported in Middle Eastern countries and have been responsible for widespread and serious disease in commercial chickens in Iran, Pakistan, Saudi Arabia and United Arab Emirates (Naeem et al., 1999; Banks et al., 2000; Nili and Asasi, 2002, 2003; Alexander, 2003; Capua and Alexander, 2004; Aamir et al., 2007). Earlier pathogenesis studies revealed that LPAI viruses are pneumotropic following intranasal inoculation (Swayne and Slemons, 1994).

Data collected from recent avian influenza outbreaks indicate that LPAI virus may mutate and become HPAI (Garcia et al., 1996; Perdue et al., 1997) and therefore to cause extremely complex situations with dramatic effects on the poultry industry. The majority of death caused by A/Chicken/Iran/SH-1 10/99 (H9N2) avian influenza virus in commercial broiler farms of Iran might be due to renal

Corresponding Author: Mohammad Mehdi Hadipour, Department of Veterinary Clinical Sciences, Islamic Azad University, Kazerun Branch, Kazerun, Iran 
damage, so the aim of this study was to investigate the nephropathogenicity of A/Chicken/Iran/SH-110/99 (H9N2) avian influenza virus following Intratracheal (IT) inoculation of this isolate in commercial broiler chickens.

\section{MATERIALS AND METHODS}

Experimental design: Sixty 20 days old broiler chickens were randomly divided in 2 equal groups (test and control) and were housed in the same condition in two separate rooms. Chickens were monitored on a daily basis for general condition and the presence of clinical signs. Subsequently, the test group was inoculated intratracheally with $10^{6} \mathrm{EID}_{50}$ per bird of $\mathrm{A} /$ Chicken/Iran/SH-1 10/99 (H9N2) avian influenza virus at 20 days of age.

Five birds from each group were randomly selected on days $1,2,4,6,8$ and 10 Post-Inoculation (PI). Then they were humanly sacrificed and were subjected to throughout necropsy. Gross lesions were recorded and samples of kidney were collected for histopathologic studies.

Light microscopy: Tissue samples were taken from each of five inoculated and uninoculated chickens and then fixed in $10 \%$ neutral buffered formalin solution. Tissue samples were routinely processed to paraffin wax blocks and five micrometer sections were prepared and stained with Haematoxylin-Eosin ( $\mathrm{H}$ and $\mathrm{E})$ stain for light microscopic examination.

\section{RESULTS AND DISCUSSION}

Clinical findings: Daily monitoring did not show any changes in clinical behaviour of the birds in control group. Infected chickens showed clinical signs such as depression, puffing, oedema of face and head, conjunctivitis and ruffled feathers on days 2-4 PI.

Gross necropsy findings: Control chickens did not show any gross lesions. However, the most frequent gross lesions in infected birds were turbidity of the thoracic and abdominal air sacs, mild congestion of the trachea and lung, mild accumulation of fibrinous exudate on the tracheal mucosa, decrease size of bursa of Fabricius and abnormal kidney. Thymus did not show obvious gross lesions.

Histopathology: In the control chickens ( 30 birds) all of the examined organs were histologically normal and there was no detectable lesion. The results of histopathology in kidney of inoculated group (30 birds) are as follow: Lymphocytic tubulointerstitial nephritis was predominant histologic change observed in the kidney on days 6,8 and 10 PI (Fig. 1,2). The frequency of histologic changes in kidney was $26.6 \%$. Although, experimental study of low pathogenic AI viruses in SPF chicken produce no or low mortality, frequent high mortality rates have been reported in the field cases (Nili and Asasi, 2002, 2003; Naeem et al., 1999; Bano et al., 2003).

This experiment was conducted to study the nephropathogenicity of H9N2 AIV in the commercial broiler chickens. Histopathologic study of experimental intratracheal infection of chickens with Iranian AIV H9N2 isolate revealed that the virus is epitheliotropic and produced tubulointerstitial nephritis in commercial broiler chickens. In this study, the clinical sign and lesions found at postmortem examination were almost similar and milder than lesions produced in naturally infected chickens during H9N2 AIV outbreak in Iran and in Pakistan (Naeem et al., 1999; Nili and Asasi 2002, 2003;

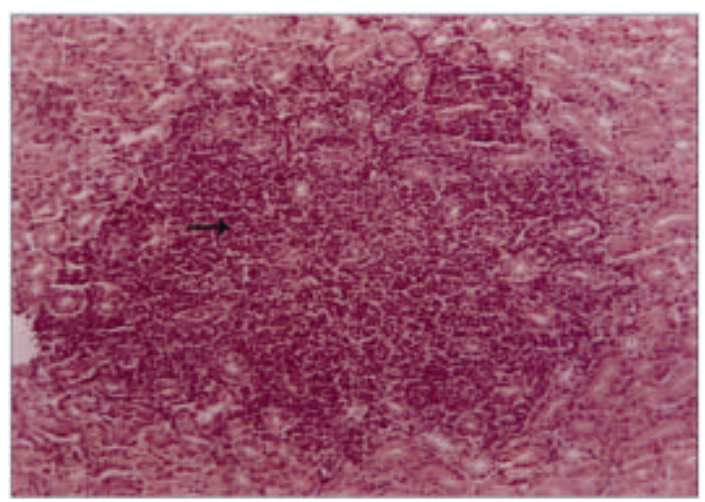

Fig. 1: Large aggregate of lymphocytes in the interstitial tissues of the kidney (black arrow) 8 days PI (H and $\mathrm{E} \times 100$ )

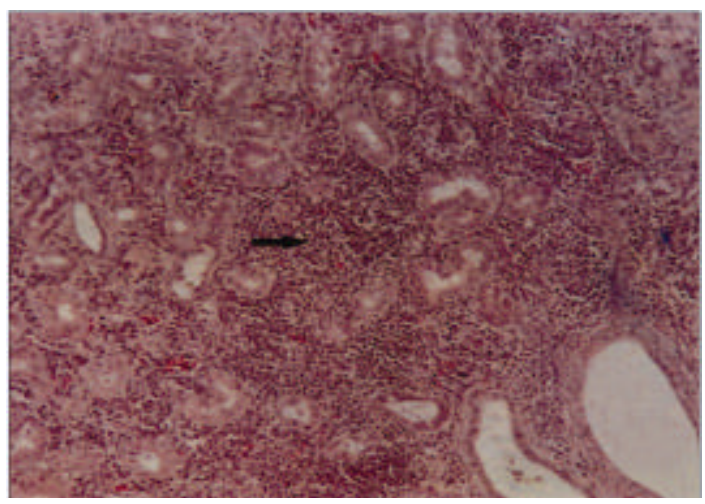

Fig. 2: Lymphocytic tubulointerstitial nephritis (black arrow) 10 days $\mathrm{PI}(\mathrm{H}$ and $\mathrm{E} \times 200)$ 
Bano et al., 2003). However, frequent cast formation in the tracheal bifurcation which has been reported in field cases of H9N2 avian influenza outbreaks were not observed in this experiment. This finding shed some light on the H9N2 problem in Iran and some other Middle East countries which has been reported to be associated with cast formation in the tracheal bifurcation. This could be due to mixed infection with other respiratory pathogens such as infectious bronchitis virus in field situation (Nili and Asasi, 2002, 2003).

Recent studies indicate that co-infection of even infectious bronchitis live vaccine with H9N2 AI virus not only increased the severity of H9N2 AIV clinical sings and gross lesions but also increased the mortality rate due to the synergistic effects of both viruses on kidney and subsequent severe renal failure (Haghighat-Jahromi et al., 2007,2008 ). In some researches (Slemons and Swayne, 1990, 1995; Slemons et al., 1990; Swayne and Slemons, 1990, 1992, 1994; Swayne et al., 1994; Swayne and Pantin-Jackwood, 2006), inoculation of chickens by Intranasal (NN) and Intratracheal (IT) route with low virulence chicken or duck-origin influenza virus isolates produced mortality and kidney lesions in 1 day old chickens and adult hens. However in other studies absence of mortality has been reported (Swayne et al., 1994; Shalaby et al., 1994).

In the current study, presence of inflammation and infiltration of lymphocytes in the renal tissues indicate that the A/Chicken/Iran/SH-110/99 (H9N2) avian influenza virus has pathogenicity for kidney of commercial broiler chickens. Hablolvarid et al. (2004) inoculated 5 weeks old chickens with an isolate of H9N2 avian influenza virus by intratracheal route. Tubulointerstitial nephritis and pancreatitis were the most frequent histologic changes. Influenza nucleoprotein was demonstrated in the kidney and pancreas of inoculated chickens. Bano et al. (2003) inoculated an isolate of H9N2 avian influenza virus to chickens using different routes and subsequently challenged with other infectious agents. The AIV antigen was detected in the trachea, lung, kidney and cloacal bursa among infected birds. Mo et al. (1997) inoculated chickens inoculated 4 weeks old SPF chickens intratracheally with A/Chicken/ Pennsylvania/ 21525/83 (H5N2) and histologic lesions were seen in lymphoid organs and kidney. In another study after intravenous inoculation of avirulent $\mathrm{H} 4 \mathrm{~N} 4, \mathrm{H} \curvearrowleft \mathrm{N} 2$ and $\mathrm{H} 3 \mathrm{~N} 8$ viruses into chickens, specific lesions and immunoperoxidase staining were noted in the kidney only (Hooper et al., 1995). As abdominal air sacs are next to kidneys, presumably, presence of nephritis foci in the kidneys during 6-10 days PI could be resulted from infection of the respiratory tract (air sacs). Regarding kidney lesions, the result obtained from the present study is in agreement with finding by Slemons et al. (1990). This finding indicate that renal failure resulted from kidney lesion could be encountered in H9N2 AIV infection in chicken.

\section{CONCLUSION}

The presence of abnormal kidney in gross necropsy findings, concurrent with histologic lesions were seen in the renal tissue in this study indicate that the $\mathrm{A} /$ Chicken/Iran/SH-110/99 (H9N2) isolate is epitheliotropic which in IT route of inoculation has pathogenicity for the kidney (nephrotropic).

\section{ACKNOWLEDGEMENTS}

The researchers thanks the Pathology Department Staff of Shiraz University of Medical Sciences and Histopathology Laboratory Staff of Chamran Hospital for technical assistance in preparing histopathologic sections.

\section{REFERENCES}

Aamir, U.B., U. Wernery, N. Ilyushina and R.G. Webster, 2007. Characterization of avian H9N2 influenza viruses from United Arab Emirates 2000 to 2003. Virology, 361: 45-55.

Alexander, D.J., 2000. A review of avian influenza in different bird species. Vet. Microbiol., 74: 3-13.

Alexander, D.J., 2003. Report on avian influenza in Eastern hemisphere during 1997-2002. Avian Dis., 47: 792-797.

Banks, J., E.C. Specidel, P.A. Harris and D.J. Alexander, 2000. Phylogenetic analysis of influenza A viruses of H9 hemagglutinin subtype. Avian Pathol., 29: 353-360.

Bano, S., K. Naeem and S.A. Malik, 2003. Evaluation of pathogenic potential of avian influenza virus serotype H9N2 in chickens. Avian Dis., 47: 817-822.

Brown, I.H., J. Banks, R.J. Manvell, S.C. Essen and W. Shell et al., 2006. Recent epidemiology and ecology of influenza A viruses in avian species in Europe and the Middle East. Dev. Biol., 124: 45-50.

Capua, I. and D.J. Alexander, 2004. Avian influenza: Recent development. Avian Pathol., 33: 393-404.

Capua, I., F. Mutinelli, S. Marangon and D.J. Alexander, 2000. H7N1 avian influenza in Italy (1999 to 2000) in intensively reared chickens and turkeys. Avian Pathol., 29: 537-543. 
Fedorko, D.P. and N.A. Nelson, 2006. Performance of rapid tests for detection of avian influenza a virus types H5N1 and H9N2. J. Clin. Microbiol., 44: 1596-1597.

Garcia, M., J.M. Crawford, J.M. Latimer, E. Rivera-Cruz and M.L. Perdue, 1996. Heterogeneity in the hemagglutinin gene and emergence of the highly pathogenic phenotype among recent H5N2 avian influenza viruses from Mexico. J. Gene. Virol., 77: 1493-1504.

Hablolvarid M.H., I.S. Haghdost, S.A. Pourbakhsh and M.R. Gholami, 2004. Histopathological study of intratracheally inoculated A/Chicken/Iran/259/1998 (H9N2) influenza virus in chicken. Arch. Razi Ins., 58: $51-62$.

Haghighat-Jahromi, M., K. Asasi, H. Nili and H. Dadras, 2007. Role of infectious bronchitis live vaccine on pathogenicity of H9N2 avian influenza virus. Int. J. Poult. Sci., 6: 838-841.

Haghighat-Jahromi, M., K. Asasi, H. Nili, H. Dadras and A.H. Shooshtari, 2008. Coinfection of avian influenza virus (H9N2 subtype) with infectious bronchitis live vaccine. Arch. Virol., 153: 651-655.

Hooper, P.T., G.W. Russell, P.W. Selleck and W.L. Stanislawek, 1995. Observations on the relationship in chickens between the virulence of some avian influenza viruses and their pathogenicity for various organs. Avian Dis., 39: 458-464.

Li, C., K. Yu, G. Tian, D. Yu and L. Liu et al., 2005. Evolution of H9N2 influenza viruses from domestic poultry in Mainland China. Virology, 340: 70-83.

Li, K.S., K.M. Xu, J.S.M. Peiris, L.L.M. Poon and K.Z. Yu et al., 2003. Characterization of H9 subtype influenza viruses from the ducks of southern china: A candidate for the next influenza pandemic in humans? J. Virol., 77: 6988-6994.

Liu, J.H., K. Okazaki, W.M. Shi, Q.M. Wu, A.S. Mweene and H. Kida, 2003. Phylogenetic analysis of neuraminidase gene of H9N2 influenza viruses prevalent in chickens in china during 1995-2002. Virus. Genes, 27: 197-202.

Mo, I.P., M. Brugh, O.J. Fletcher and D.E. Swayne, 1997. Comparative pathology of chickens experimentally inoculated with avian influenza viruses of low and high pathogenicity. Avian Dis., 41: 125-136.

Naeem, K., A. Ulah, R. J. Manvell and D.J. Alexander, 1999. Avian influenza subtype H9N2 in poultry in Pakistan. Vet. Rec., 145: 560-560.

Nili, H. and K. Asasi, 2002. Natural cases and an experimental study of H9N2 avian influenza in commercial broiler chickens of Iran. Avian Pathol., 31: $247-254$.
Nili, H. and K. Asasi, 2003. Avian influenza (H9N2) outbreak in Iran. Avian Dis., 47: 828-831.

Perdue, M.L., M. Garcia, D. Senne and M. Fraire, 1997. Virulence associated sequence duplication at the hemagglutinin cleavage site of avian influenza viruses. Virus Res., 49: 173-186.

Perez, D.R. W. Lim, J.P. Seiler, G. Yi, M. Peiris, K.F. Shortridge and R.G. Webster, 2003a. Role of quail in the interspecies transmission of H9 influenza a viruses: Molecular changes on HA that correspond to adaptation from ducks to chickens. J. Virol., 77: 3148-3156.

Perez, D.R., R.J. Webby, E. Hoffmann and R.G. Webster, 2003b. Land-based birds as potential disseminators of avian mammalian reassortant influenza $A$ viruses. Avian Dis., 47: 1114-1117.

Ron, A.M.F., V. Munster, A. Wallensten, T.M. Bestebroer and S. Herfst, 2005. Characterization of a novel influenza A virus haemagglutinin subtype (H16) obtained from black-headed gulls. J. Virol., 79: 2814-2822.

Shalaby, A.S., R.D. Slemons and D.E. Swayne, 1994. Pathological studies of A/Chicken/Alabama/7395/75 (H4N8) influenza a virus in specific pathogen-free laying hens. Avian Pathol., 24: 623-632.

Slemons, R.D. and D.E. Swayne, 1990. Replication of a water fowl-origin influenza virus in the kidney and intestine of chicken. Avian Dis., 34: 227-234.

Slemons, R.D. and D.E. Swayne, 1995. Tissue tropism and replicative properties of waterfowl-origin influenza viruses in chickens. Avian Dis., 39: 521-527.

Slemons, R.D., L.N. Locke, M.G. Sheerer, R.M. Duncan and V.S. Hinshaw, 1990. Kidney lesions associated with mortality in chickens inoculated with waterfowl influenza viruses. Avian Dis., 34: 120-128.

Swayne, D.E. and M. Pantin-Jackwood, 2006. Pathogenicity of avian influenza viruses in poultry. Dev. Biol., 124: 61-67.

Swayne, D.E. and R.D. Slemons, 1990. Renal pathology in specific-pathogen-free chickens inoculated with a waterfowl-origin type A influenza virus. Avian Dis., 34: 285-294.

Swayne, D.E. and R.D. Slemons, 1992. Evaluation of the kidney as a potential site of avian influenza virus persistence in chickens. Avian Dis., 36: 937-944.

Swayne, D.E. and R.D. Slemons, 1994. Comparative pathology of a chicken origin and two duck origin influenza virus isolated in chicken, the effects of route of inoculation. Vet. Pathol., 31: 237-245.

Swayne, D.E., 2007. Understanding the complex pathobiology of high pathogenicity avian influenza viruses in birds. Avian Dis., 50: 242-249. 
Swayne, D.E., M.J. Radin and R.D. Slemons, 1994. Acute renal failure as the cause of death in chickens following intravenous inoculation with avian influenza virus A/Chicken/Alabama/7395/75(H4N8). Avian Dis., 38: 151-157.

Xu, C., W. Fan, R. Wei and H. Zhao, 2004. Isolation and identification of swine influenza recombinant A/Swine/Shandong/1/2003(H9N2) virus. Microbes Infec., 6: 919-925.
Xu, K.M., G.J.D. Smith, J. Bahl, L. Duan and H. Tai et al., 2007b. The genesis and evolution of H9N2 influenza viruses in poultry from Southern China, 2000 to 2005. J. Virol., 81: 10389-10401.

Xu, K.M., K.S. Li, G.J. Smith, J.W. Li and H. Tai et al., 2007a. Evolution and molecular epidemiology of H9N2 influenza A viruses from quail in southern China, 2000 to 2005. J. Virol., 81: 2635-2645. 